\title{
Water Poverty Index Calculation: Additive or Multiplicative Function?
}

\author{
Charles van der Vyver
}

\author{
North-West University, Vaal Triangle Campus. Vanderbijlpark, South Africa
}

Correspondence should be addressed to: Charles van der Vyver; Charles.vandervyver@nwu.ac.za

Received date: 18 April 2013; Accepted date: 20 June 2013; Published date: 27 August 2013

Copyright $@$ (2013. Charles van der Vyver. Distributed under Creative Commons CC-BY 3.0

\begin{abstract}
As South Africa is a water-stressed country, determining how to most efficiently use its already scarce water resource is of utmost importance. This research aims to quantify the difference in the water poverty index when calculated with the additive function compared to the multiplicative function. A case study is performed with the Vaal Triangle region in South Africa, which is a relatively small scale with data at a high assurance level. After calculating the indices for the three towns in the region, it is found that there are only small differences in the obtained values. The multiplicative function consistently produced lower index values, but the final recommendation of the town most in need of an intervention would have remained unchanged. It is concluded that some of the factors that might influence the choice of function include the chosen scale, components and sub-components used, and data sources, amongst others. Future research should focus on refining the existing functions and on developing guidelines for index calculation.
\end{abstract}

Keywords: Water management, water poverty index, additive function, multiplicative function.

\section{Introduction}

In recent years it has been widely recognised that water was managed with little regard to the efficiency of its utilisation and with no or very little effective pollution control (Pallett, 1997), and according to Sullivan \& Meigh (2007) there is a definite link between human welfare and the environment. South Africa, being a water-stressed country with less than $1700 \mathrm{~m}^{3}$ of water for each person per year (Rand Water, 2008), has limited fresh water resources and budgets for the supply of basic infrastructure services. Currently over 6 million people in South Africa are without access to even a basic level of water supply or have only a very limited level of access (Cullis, 2005). The provision of reliable, sustained and safe water to people worldwide has become a top priority on the international agenda (Garriga \& Foguet, 2010; Komnenic, Ahlers \& van der Zaag, 2009).

The norm has been to think of water poverty purely in terms of a lack of the actual resource; however, Sullivan et al., (2003) and Sullivan et al., (2005) have

Cite this Article as: Charles Van der Vyver (2013), " Water Poverty Index Calculation: Additive or Multiplicative Function?" Journal of South African Business Research, Vol. 2013 (2013), Article ID 615770, DOI: $10.5171 / 2013.615770$. 
shown that water poverty should be expressed in terms of resource, access, capacity, use and environment. These five components are contained in the Water Poverty Index (WPI) as developed by Sullivan et al., (2002), and refined by researchers at the Centre for Ecology and Hydrology in Wallingford, United Kingdom. The WPI aims to target political and financial attention towards those most in need.

\section{Demarcation}

South Africa is a water-stressed country (Rand Water, 2008). Water stress is an indicator that is commonly used to measure the degree of water resources vulnerability, and typically occurs when the demand for water exceeds the supply (Perveen \& James, 2011). Water stress causes deterioration of fresh water resources in terms of quantity and quality. Water scarcity occurs when a large number of people in an area do not have access to safe and affordable water to satisfy their needs for drinking, washing or their livelihoods for a significant period of time (Rijsberman, 2005). Rand Water (2008) warns that if South Africans do not learn how to use their limited water supplies wisely, they will move into a water scarcity category - that is, less than $1000 \mathrm{~m}^{3}$ per person per year - by 2025. On a worldwide scale the World Bank estimates that roughly 166 million people in 18 countries are affected by water scarcity and another 270 million people in 11 countries are water stressed (Hemson et al., 2008).

This research addresses some of the various needs that were highlighted in the 1994 Reconstruction and Development Program (RDP), which listed "meeting basic needs" as one of its five broad programmes (Melville and Goddard, 1996). Some of the areas that were highlighted in the RDP as being extremely relevant, and therefore in need of research include, amongst others:

- Water, including its provision, sanitation and conservation.

- $\quad$ Social welfare.
This research, either directly or indirectly, assists in addressing all of these needs.

The accuracy of the WPI increases as the resolution increases (Komnenic et al., 2009), and this was one of the main contributing factors for this study to focus on the municipal/household level. "In order to develop effective policy guidance it is essential that any assessment tool be applied at the appropriate scale", Sullivan \& Meigh (2007:123). One of the two local municipalities in the demarcated area in South Africa is the Emfuleni local municipality (ELM). The ELM consists of the two main towns Vanderbijlpark and Vereeniging, along with their surrounding townships and settlements. The other municipality in the area is the Metsimaholo local municipality (MLM), which consists mainly of the town Sasolburg, along with its surrounding townships and settlements. The ELM has highlighted some challenges that they foresee with regards to their water and sanitation services. These challenges include:

- An ageing water infrastructure.

- A limited preventative maintenance program due to a shortage of personnel.

- $\quad$ Rapid development.

- Flat rate billing for water consumption in certain areas.

- Un-metered areas.

In the ELM area, Metsi-a-Lekoa is responsible for the distribution of potable water, the collection and conveyance of wastewater, and the treatment of the wastewater. Metsi-A-Lekoa is the dedicated water services authority entity for the ELM and its core functions are the water and sanitation functions of the municipality.

They utilize some of the assets of the municipality to accomplish these tasks, and are also responsible for the maintenance and the costs of the water services systems (ELM, 2010). 
As in the rest of South Africa, unemployment continues to remain a problem in the demarcated area. The lack of access to sustained safe water leads to a decrease in productivity, which in turn results in the poverty of that society (Komnenic et al., 2009). This in turn leads to a high dependency ratio within the municipality, which directly hampers the ability of the population to save and/or engage in other entrepreneurial activities (ELM, 2010). The dependency ratio refers to the amount of unemployed people depending on the municipality for basic services, without being able to pay for it or without making any sort of economical contribution. Ideally, this ratio should be as close as possible to 0 . The economic growth for the municipality has been quite slow when compared to the targets that were set for the region by the Gauteng Growth and Development Strategy (GGDS). For the period from 1995 - 2000 the growth rate was $0.4 \%$, for $2000-2006$ it was $1.8 \%$, for $2006-2011$ it is projected to be $1.1 \%$, and for the period from 2011 2016 it is also expected to be in the region of $1 \%$ (ELM, 2010).

\section{Water Management}

During recent years some of the major shortcomings of national water management that have been widely recognised (Clarke and King, 2004; Langford, 2005; Meyer, 2007; Pallett, 1997) include very little or no pollution control, and inefficient utilisation. According to Pallett (1997), the aim of water management should be to supply people with essential water supplies, while ensuring that water continues to be shared among all the components of the human and natural environment in a river basin. The importance of good water management is vital in determining the water fate of the majority of the world's population (Clarke and King, 2004).

Management is one of the major problems in the global water sector (Ahmad, 2003), and according to Langford (2005), the reasons why we currently find ourselves in a water and sanitation crisis are:
- Insufficient and decaying infrastructure for water service delivery, especially in deprived rural and urban areas.

- Insufficient capacity and funding for the expansion and maintenance of water supply systems.

- Pollution of traditional water sources, particularly from industrial waste, agricultural runoff and human and animal waste.

- $\quad$ Reduced access to, and depletion of, water resources due to drought, population growth, armed conflict and the dominance of commercial agricultural and industrial activities.

Many researchers (Ahmad, 2003; Cullis, 2005; Sullivan et al., 2002) suggest that a shift of emphasis to a more holistic approach to water management is necessary. As a first step, the concept of an Integrated Water Resource Management (IWRM) as a holistic approached-based framework for water management was introduced. This approach focuses on poverty reduction and sustainability of ecosystems among other things; in other words to achieve a sustainable water world. The Global Water Partnership (2000:15) defines IWRM as "a process which promotes the co-ordinated development and management of water, land, and related resources in order to maximise the resultant economic and social welfare in an equitable manner without compromising the sustainability of vital ecosystems".

At the United Nations Conference on the Environment and Development that was held in 1992 in Rio de Janeiro, IWRM was a major item on the agenda. During this conference the various stakeholders came up with an action plan for the world environmental crisis, called Agenda 21. Under this agenda, the four main objectives of IWRM are (Pallett, 1997): 
1. To plan the sustainable and rational utilisation, protection, conservation and management of water resources.

2. To identify and strengthen or develop, as required, in particular in developing countries, the appropriate institutional, legal and financial mechanisms to ensure that water policy and its implementation are a catalyst for sustainable social progress and economic growth.

3. To promote a dynamic, iterative, interactive and multisectoral approach to water resources management.

4. To design, implement and evaluate projects and programmes that are both economically efficient and socially appropriate within clearly defined strategies.

Unfortunately, according to Swatuk (2010), although supporting the principle of IWRM, South Africa will experience some difficulties in realising the ideals of IWRM in practice. Examples of some of the contributing factors to these expected difficulties include:

- $\quad$ The loss of more than 1000000 jobs in the first post-apartheid decade, which had resulted in major economic implications.

- Fault lines that have appeared within and between the major political parties.

- Capital flight and the outmigration of skilled workers to other countries, which limit the capacity of the state and society to shift toward more efficient, equitable and sustainable processes of wealth creation.

It is felt that when the WPI (discussed in the next section) is fully robust and able to be incorporated with other water management tools, it will contribute to the achievement of IWRM, which is a stated policy goal for most nations today (Sullivan \& Meigh, 2007).

\section{Research Methodology}

Under the quantitative methodology researchers use the scientific method, which starts with the specific theory and hypotheses, and then quantitatively measure and analyze based on established research procedures (Swanson et al., 2005). It typically consists of five steps which include:

1. Determining the basic questions to be answered by the research. In this study, to compare the additive and multiplicative functions for water poverty index calculation.

2. Determining the participants in the research. Quantitative research benefits greatly from generalizability, or being able to draw conclusions about a population from sample data. In this study, to use the component scores compiled by Van der Vyver \& Jordaan (2012) as the basis for a case study.

3. Selection of methods to answer the research questions. In this study, using secondary data as the starting point for new calculations.

4. Selection of statistical analysis tools for analyzing the collected data. In this study, satisfied through the use of data at a high significance level as a result of the chosen sources.

5. Performing the interpretation of the results of the analysis based on the statistical significance determined.

The advantages of a case study as a research strategy include (Denscombe, 2003): 
- It allows the researcher to deal with the subtleties and intricacies of complex situations.

- It allows the use of a variety of research methods.

- It fosters the use of multiple sources of data.

- It is suitable for when the researcher has little control over events.

- Concentrates effort on one research site.

- Suitable to both theory-building and theory-testing research.

The research makes use of secondary data which has been collected and processed previously by the author. By using secondary data a lot of time and financial constraints are overcome.

\section{The Water Poverty Index}

The conventional methods to assess water management were purely deterministic, relying on the availability of large-scale data. A method that is easy to calculate, cost effective to implement, based mostly on existing data, and that uses a transparent process (i.e. easy to understand) was needed by policy makers and funding agencies. This motivated Sullivan et al., (2002) to design the WPI as an alternative water situation assessment tool. The WPI has the following advantages over conventional methods (Komnenic et al., 2009; Sullivan \& Meigh, 2007):

- It is a mechanism to prioritise water needs.

- It provides a better understanding of the relationship between the physical availability of water, its ease of abstraction, and the level of welfare.

- $\quad$ The WPI is mainly designed to help improve the situation for people facing poor water endowments and poor adaptive capacity.

- It is a tool for monitoring progress in the water sector.

- It provides a reasonably simple process to combine biophysical, social, economic and environmental data to produce a single index value.

The WPI captures the whole range of issues related to water resources availability as well as their impacts on people (Sullivan et al., 2005). The primary goals were to enable holistic water-resource assessments on a site-specific basis at the community level, and to be a water management tool which was accessible to water decision makers at various levels. The WPI allows the use of different scales to be applied for different needs and defines water poverty according to five components. These component variables, which capture a more comprehensive picture of water management challenges (Sullivan et al., 2003), are the following:

- Resources: The availability of water, taking into account the variations in seasonal and interannual fluctuations and water quality.

- Access: The accessibility of water for human use taking into account the distance to a safe source and the time needed to collect the water for household and other needs - including the irrigation of crops and for industrial use.

- Capacity: The ability to effectively manage water.

- Use: This captures the actual amount of water being used and extracted from the system. Use includes domestic, agricultural and industrial use (Lawrence et al., 2002).

- Environment: This variable captures the environmental impact 
of water management with the intention to ensure long-term ecological integrity. "Environmental factors which are likely to impact on regulation will affect capacity" (Lawrence et al., 2002:1).

It should be noted that proposing one fixed set of indicators for each and every context is not appropriate, as each location is unique and specific criteria and indicators may not be available for all cases (Garriga \& Foguet, 2010).

A composite index approach is used to calculate the WPI (Cullis, 2005). Each of the five components consists of a number of sub-components and a weighting can be applied to each component to indicate the component's importance. The components are standardised to fall in the range 0 to 100 , resulting in a final WPI value between 0 and 100 . The highest value, 100 is taken as the best situation with 0 being the worst. The purpose of the weightings is to emphasise a specific component of the WPI structure, and the importance of any component should not be predetermined by researchers as it is clearly a political decision (Sullivan et al., 2005).

This comprehensive approach to measuring water poverty was taken forward by researchers at the Centre for
Ecology and Hydrology in Wallingford, UK. They refined the WPI that was developed by Sullivan et al., (2002) in an attempt to quantify the link between water and poverty by combing hydrological data with socio-economic data to provide a complex indicator that reflects the true nature of a community and its access to clean water (Schulze and Dlamini, 2002). These researchers, along with experts from the World Water Council, calculated the WPI for 147 countries all over the world (World Water Forum, 2003). The World Water Council is an independent, international organisation incorporated as a French notfor-profit association with over 250 member organisations based in over 60 countries. South Africa scored a WPI value of 52 , which places it in the lower $50 \%$. Considering that 100 is the perfect goal score, its score of 52 places South Africa roughly in the middle order. The majority of countries in the top ten are in the developed world, are water rich, and have extreme winters (i.e. snowfall), whereas all the countries in the lowest ten positions are in the developing world where there are relatively mild winters, and underdevelopment plays a larger role in water poverty than the availability of the resource.

Table 1 contains the component scores for the demarcated area with their associated weightings as compiled by Van der Vyver \& Jordaan (2012).

Table 1: Component scores

\begin{tabular}{|l|c|c|c|c|c|}
\hline & $\begin{array}{c}\text { Resource } \\
\text { (Weighting=1) }\end{array}$ & $\begin{array}{c}\text { Access } \\
\text { (Weighting=2) }\end{array}$ & $\begin{array}{c}\text { Capacity } \\
\text { (Weighting=2) }\end{array}$ & $\begin{array}{c}\text { Use } \\
\text { (Weighting=1) }\end{array}$ & $\begin{array}{c}\text { Environment } \\
\text { (Weighting=1) }\end{array}$ \\
\hline Vanderbijlpark & 100 & 95.564 & 41.344 & 80.401 & 81.72 \\
\hline Vereeniging & 100 & 92.217 & 38.963 & 89.113 & 72.82 \\
\hline Sasolburg & 100 & 97.541 & 47.745 & 71.296 & 77.12 \\
\hline
\end{tabular}

(Source: Van der Vyver \& Jordaan, 2012) 


\section{Additive Function}

The five key components of the WPI are combined together in the additive function as follows:

$$
W P I=\frac{w_{r} R+w_{a} A+w_{c} C+w_{u} U+w_{e} E}{w_{r}+w_{a}+w_{c}+w_{u}+w_{e}}
$$

Where

WPI $=$ Water Poverty Index score of a particular location

$\mathrm{R}=$ Resources component (score out of 100)

$A=$ Access component (score out of 100)
C = Capacity component (score out of 100)

$\mathrm{U}=$ Use component (score out of 100)

$\mathrm{E}=$ Environment component (score out of 100)

$\mathrm{w}=$ weighting factor for each component

Some of the major advantages of the additive function include simplicity, transparency, and ease of understanding for non-experts.

Therefore the WPI for Vanderbijlpark is:

$$
W P I=\frac{(1 * 100)+(2 * 95.564)+(2 * 41.344)+(1 * 80.401)+(1 * 81.72)}{1+2+2+1+1}=76.562
$$

The WPI for Vereeniging is:

$$
W P I=\frac{(1 * 100)+(2 * 92.217)+(2 * 38.963)+(1 * 89.113)+(1 * 72.82)}{1+2+2+1+1}=74.899
$$

And the WPI for Sasolburg is:

$$
W P I=\frac{(1 * 100)+(2 * 97.541)+(2 * 47.745)+(1 * 71.296)+(1 * 77.12)}{1+2+2+1+1}=76.998
$$

\section{Multiplicative Function}

The five key components of the WPI are combined together in the multiplicative function as follows:

$$
W P I=\sqrt[n]{\prod x_{i}^{w_{i}}}
$$


Where

WPI = Water Poverty Index score of a particular location

$\mathrm{x}_{\mathrm{i}}=$ component $i$ of the WPI structure (R, A, C, U, E)

$\mathrm{W}_{\mathrm{i}}=$ weighting factor for each component $\mathrm{n}=$ sum of the assigned weightings

When compared to the additive function, the multiplicative function does tend to penalize poor performance in components more heavily (Garriga \& Foguet, 2010), and more accurately identifies the hot spots of the data set.

Therefore the WPI for Vanderbijlpark is:

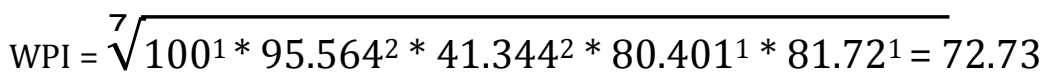

The WPI for Vereeniging is:

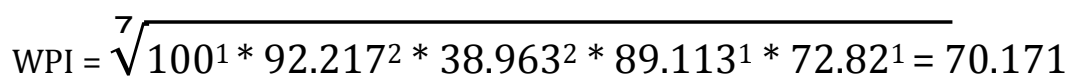

And the WPI for Sasolburg is:

$\mathrm{WPI}=\sqrt[7]{100^{1} * 97.541^{2} * 47.745^{2} * 71.296^{1} * 77.12^{1}=} 73.802$

\section{Comparison and Discussion}

When constructing any composite index, the choice of the weighting and aggregation function will always remain a major issue (Garriga \& Foguet, 2010). Although the chosen weightings were beyond the scope of this paper (see Van der Vyver (2012) in which the impact of different weighting selections were discussed), two aggregation functions were compared. Whichever aggregation function is chosen, the following guidelines will ensure its applicability when adhered to (Sullivan et al., 2003; Kumar \& Alappat, 2004; Swamee \& Tyagi, 2000):

- The method should be free from or minimize overestimation and underestimation.

- When similar results are obtained, the method which retains the virtues of simplicity and straightforwardness is the most appropriate. 
- It should be sensitive to changes in an individual variable throughout its range.

- It can be considered successful if it is transparent and the index can be readily disaggregated into the separate components with no information lost.

Table 2 contains the WPI values obtained with each of the functions, as well as the differences between the functions for each town.

Table 2: Comparison of WPI values

\begin{tabular}{|l|c|c|c|c|}
\hline & Additive & Multiplicative & Difference & \% Difference \\
\hline Vanderbijlpark & 76.562 & 72.23 & 4.332 & 5.658 \\
\hline Vereeniging & 74.899 & 70.171 & 4.728 & 6.313 \\
\hline Sasolburg & 76.998 & 73.802 & 3.196 & 4.151 \\
\hline
\end{tabular}

Given the household scale that was applied in the study, both functions would have identified Vereeniging as being the most in need of an intervention, and more specifically improving educational and income capacity. Although the order of the three towns also remained unchanged, the percentage changes between the towns did increase. As mentioned in section 7, the multiplicative function did penalize the poor performance of the capacity component for Vereeniging. It can therefore be argued that there are several factors which can influence the choice of calculation function. These include, and are not limited to, the chosen scale, the components and sub-components used, and the chosen data sources (Cullis, 2005; Sullivan et al., 2003; Sullivan et al., 2005; World Water Forum, 2003).

\section{Conclusion}

The role of the water poverty index in water poverty alleviation has been widely recognised. Its inherent flexibility in terms of scale, component choice and data sources ensure that its possible applications are nearly endless. Its construction should however always remain as transparent as possible, to ensure stakeholder buy-in.

As mentioned earlier various functions exist for the calculation of the index, each with its own advantages and disadvantages. This research compared the additive and multiplicative functions, and although the latter produced lower values in each of the three towns, the final recommendation would have remained unchanged. In this specific case study it might possibly be attributed to the chosen scale, the composition of the components, the data sources used, or some combination of the three.

Throughout the calculation process there are various choices that can influence the accuracy of the chosen function, and it is therefore critical to spend enough time and effort in determining the most relevant one.

Future research should focus on refining the available functions and on developing 
guidelines for which function is most suited to which scenario.

\section{References}

Ahmad, Q. K. 2003. Towards poverty alleviation: the water sector perspectives, Water Resources Development, 19(2), pp. 263-277.

Clarke, R. \& King, J. 2004. The Atlas of Water. Mapping the world's most critical resource. Earthscan, 8 - 12 Camden High Street, London, NW1 0JH, United Kingdom.

Cullis, J. D. S. 2005. Water poverty mapping: development and introduction using a case study at the local municipal scale for the Eastern Cape. Water Research Commission, TT 250/05, August.

Denscombe, M. 2003. The Good Research Guide, $2^{\text {nd }}$ Edition. Open University Press, 325 Chestnut Street, Philadelphia, PA 19106, USA.

Emfuleni Local Municipality (ELM). 2010. Integrated Development Plan 2009/10.

Garriga, R. G. \& Foguet, A. P. 2010. Improved Method to Calculate a Water Poverty Index at Local Scale. Journal of Environmental Engineering, November 2010, pp. 1287 - 1298.

Global Water Partnership. 2000. Towards water security: a framework for action, Stockholm, Global Water Partnership.

Hemson, D., Kulindwa, K., Lein, H. \& Mascarenhas, A. 2008. Poverty and Water. Explorations of the reciprocal relationship. Zed Books Ltd, 7 Cynthia Street, London, N1 9JF, United Kingdom.

Komnenic, V., Ahlers, R. \& van der Zaag, P. 2009. Assessing the usefulness of the water poverty index by applying it to a special case: Can one be water poor with high levels of access? Physics and Chemistry of the Earth, 34, pp. 219 - 224.

Kumar, D. \& Alappat, B. J. 2004. Selection of the Appropriate Aggregation Function for Calculating Leachate Pollution Index. Practice Periodical of Hazardous, Toxic \& Radioactive Waste Management, 8(4), pp.
$253-264$

Langford, M. 2005. The United Nations concept of water as a human right: a new paradigm for old problems? Water Resources Development, 21(2), pp. 273 282.

Lawrence, P., Meigh, J. \& Sullivan, C. 2002. The water poverty index: an international comparison. Keel Economics Research Papers, KERP 2002/19, October, 2002.

Melville, S. \& Goddard, W. 1996. Research Methodology. Juta \& Co Limited, P.O. Box 14373, Kenwyn, 7790.

Meyer, W. N. 2007. The economics of water, water for life; sanitation for dignity. Van Schaik Publishers, 1064 Arcadia Street, Hatfield Pretoria.

Pallett, J. 1997. Sharing water in Southern Africa. Desert Research Foundation of Namibia, PO Box 20232, Windhoek, Namibia.

Perveen, S. \& James, L. A. 2011. Scale invariance of water stress and scarcity indicators: Facilitating cross-scale comparisons of water resources vulnerability. Applied Geography, 31(2011), pp. 321 - 328.

Rand Water. 2008. http://www.wisa.org.za/patrons/randwat er/index2.html [2 October 2008].

Rijsberman, F. R. 2005. Water scarcity: Fact or fiction? Agricultural Water Management, 80(2006), pp. 5 - 22 .

Schulze, R. E. \& Dlamini, D. J. M. 2002. Mesoscale Indicators of Water Poverty in the Thukela Catchment, South Africa, under baseline land cover conditions. Appendix 9.14 to Sullivan, C. A., Meigh, J. R., Fediw, T. $\mathrm{S}$. Derivation and Testing of the Water Poverty Index Phase 1: Final Report. DFID.

Sullivan, C. A. \& Meigh, J. R. 2007. Integration of the biophysical and social sciences using an indicator approach: Addressing water problems at different scales. Water Resource Management, 21, 
pp. $111-128$.

Sullivan, C. A., Meigh, J. R. \& Fediw, T. S. 2002. Derivation and Testing of the Water Poverty Index Phase 1: Final Report. DFID.

Sullivan, C. A, Meigh, J. R. \& Lawrence, P. 2005. Application of the Water Poverty Index at different scales: a cautionary tale. Water International, Vol. 31(3), pp. 412 426.

Sullivan, C. A., Meigh, J. R., Giacomello, A. M., Fediw, T., Lawrence, P., Samad, M., Mlote, S., Hutton, C., Allan, J. A., Schulze, R. E., Dlamini, D. J. M., Cosgrove, W., Delli Priscoli, J., Gleick, P., Smout, I., Cobbing, J., Calow, R., Hunt, C., Hussain, A., Acreman, M. C., King, J., Malomo, S., Tate, E. L., O'Regan, D. P., Milner, S. \& Steyl, I. 2003. The Water Poverty Index: Development and application at the community scale. Natural Resources Forum, 27, pp. 1-11.

Swamee P.K. \& Tyagi, A. 2000. Describing water quality with aggregate index. Journal of Environmental Engineering, 126(5), pp. $451-455$.

Swanson, R. A. \& Holton, E. F. 3rd 2005. Research in organizations: Foundations and methods of inquiry. San Francisco, Berrett-
Koehler.

Swatuk, L. A. 2010. The State and Water Resources Development through the Lens of History: A South African Case Study. Water Alternatives, Vol. 3(3), pp.521 - 536.

Van der Vyver, C. 2012. Effects of Imprecise Weighting on the Water Poverty Index. Alleviating Digital Poverty with ICT innovation in emerging economies. Will ICT Rights make a difference? IDIA 2012 Conference Proceedings, pp. 239 - 248.

Van der Vyver, C. \& Jordaan, D.B. 2012. The application of water poverty mapping in water management. The Journal for Transdisciplinary Research in Southern Africa, 8(1), pp. 95 - 120.

World Water Forum. 2003. Water Poverty Index Yields Surprising Results. 3rd World Water Forum press release. 